\title{
Optical Density and Antimicrobial Characteristics of Georgian Propolis
}

\author{
Ketevani Gabunia \\ Department of Dentistry and Pharmacy, Akaki Tsereteli State University, 59 Tamar Mepe Street, Kutaisi 4600, Georgia
}

\begin{abstract}
Apiotherapy has been applied by Georgian people since time immemorial. Treatment with bee products in Georgia has been described in popular writings. Among bee products, honey and propolis are of most particular interest. Propolis is characterized by antimicrobial, antiviral, antioxidant, anticarcinogenic and analgesic properties. We have studied relationship between optical density and antimicrobial properties. Almost all samples of Georgian propolis are characterized by high optical density and antimicrobial activity. Studies have discovered that optical density was high in the samples of spring season. The maximal absorption values have been observed at a wavelength of 290-310 nm that is characteristic of flavonoids. Also, the sample with a relatively low optical density (Baghdati district) has exhibited antimicrobial activity that is conditioned not by polyphenols, but flavonoids.
\end{abstract}

Key words: Propolis, flavonoids, flavonones, optical density, antimicrobial activity.

\section{Introduction}

In their search for effective therapeutic agents, scientists take notice of natural products, which are rich with biologically active compounds. Such natural agents include bee products, propolis in particular.

Apiotherapy has been applied by Georgian people since time immemorial. Treatment with bee products in Georgia has been described in popular writings $[1,2]$, in medical books particularly. Propolis is a biologically active compound [3-5]. Interest of scientists towards propolis is explained by its various properties as follows: antimicrobial, antiviral, antioxidant, anticarcinogenic and analgesic characteristics [6-10] that in turn is conditioned by biologically active substances contained in them [11-15]. Propolis is characterized by high optical density that is conditioned by flavonoids. According to researchers, these compounds condition its antimicrobial activity [8, 16]. Prior to 2005, the attention of scientists was fastened on Brazilian propolis [17, 18], but currently, there are studied samples of propolis from almost all countries [19-22]. Despite fact that samples of propolis from several regions of West Georgia were studied by Makashvili in the sixties of the 20th century, and some of them were studied by us in 1997-2005, Georgian propolis remains still unknown to scientists.

We were aimed at establishing a correlation between optical density and antimicrobial characteristics of samples of propolis from the different regions of Georgia.

\section{Material and Methods}

We have used as a test material the alcohol solutions of propolis samples from 5 districts of Georgia (Baghdati, Tskhaltubo, Khoni, Chiatura, Sagarejo). We were provided with samples by beekeepers for 2 years seasonally (spring, autumn). As biological material there have been used the bacterial strains. As research methods, there have been used physical, physicochemical (spectrometry) and biological methods. For antimicrobial activity, we used a $2 \%$ alcohol solution.

The experiment:

Obtaining an extract was carried out by using the method which we developed [16]. Optical density was 
determined in a SF-46 and BV1800 spectrometers. The cuvette layer thickness was $10 \mathrm{~mm}$. As a comparison we used ethyl alcohol ( $95 \%$ VOL). We studied the propolis $0,002 \%$-alcohol solution absorption spectra in ultra-violet areas by times of year for 2 years. The results are given in Fig. 1,2.

Optical density was determined within range of 190 $\mathrm{nm}$ and $350 \mathrm{~nm}$ wave lenths. Shoulder peak observed $210 \mathrm{~nm} .290 \mathrm{~nm}-310 \mathrm{~nm}$, from 220 to $250 \mathrm{~nm}$ there is occurred shoulder reducing. At $210 \mathrm{~nm}$ wave length,

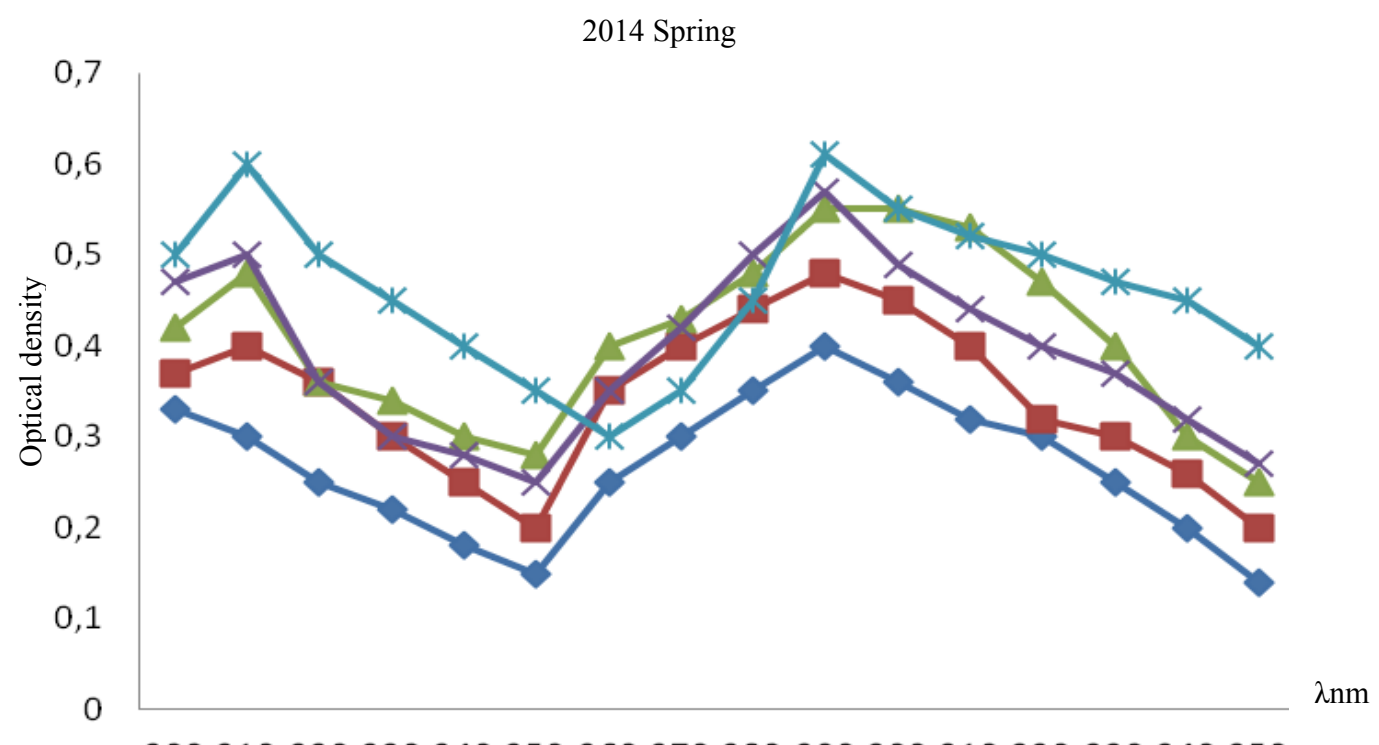

200210220230240250260270280290300310320330340350

(a)

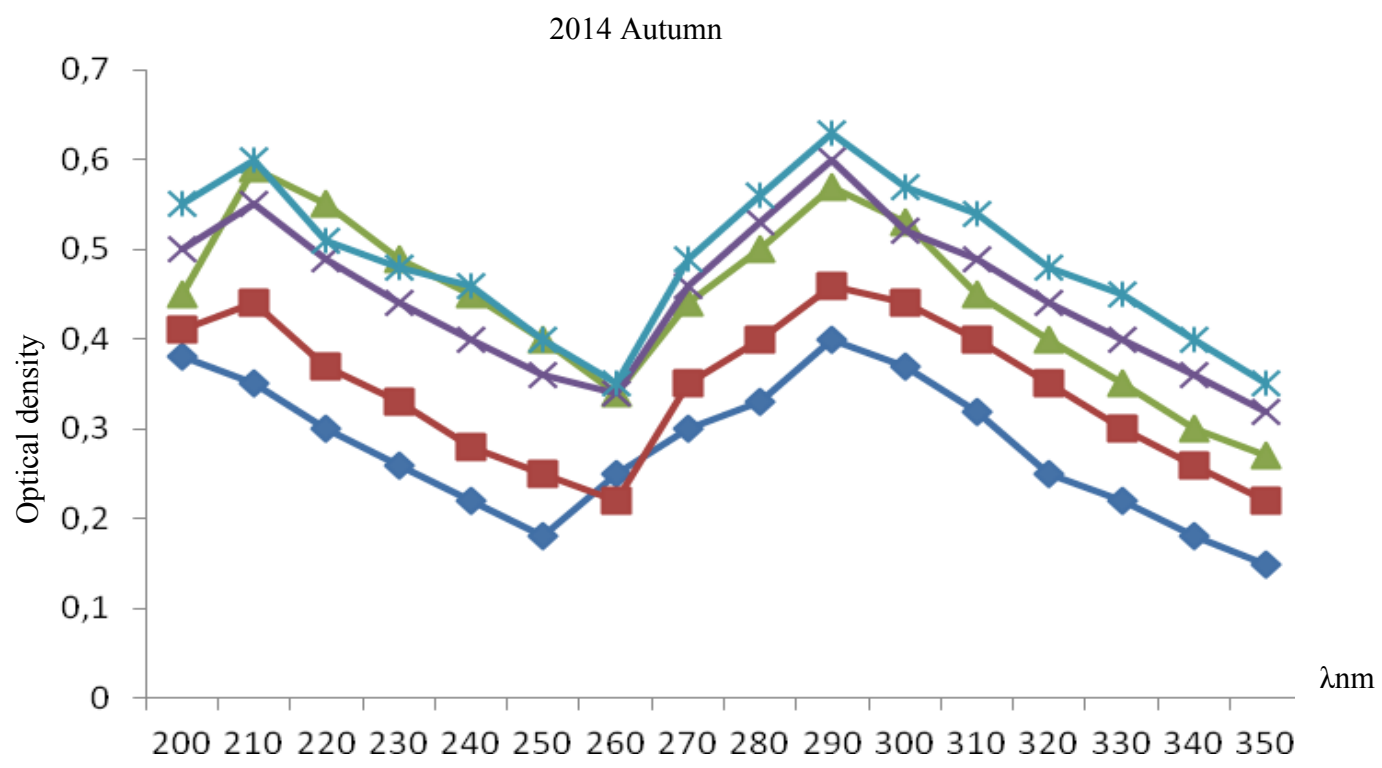

(b)

Fig. 1 The propolis $0,002 \%$-alcohol solution absorption spectra in ultra-violet areas.

1. Baghdati district.

2. Khoni district.

3. Sagarejo district.

4. Tskhaltubo district.

5. Chiatura district. 


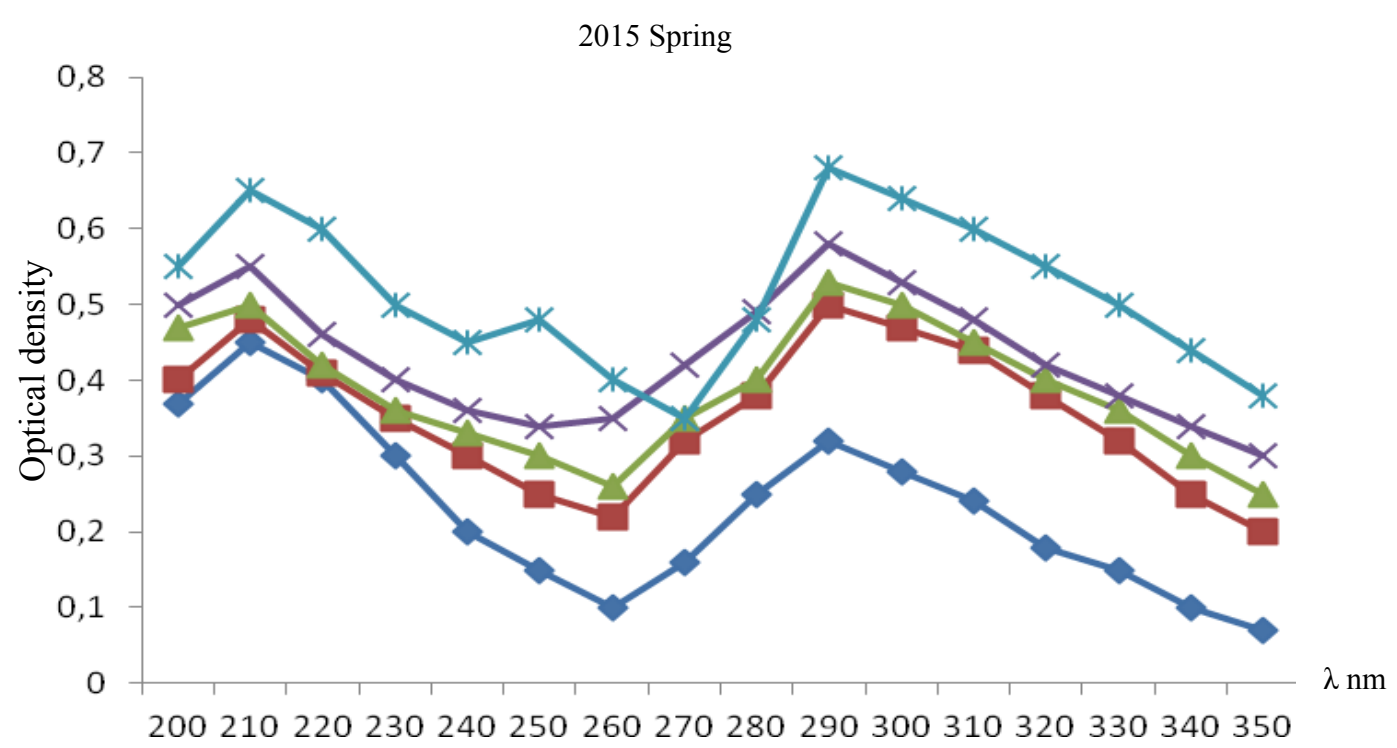

(a)

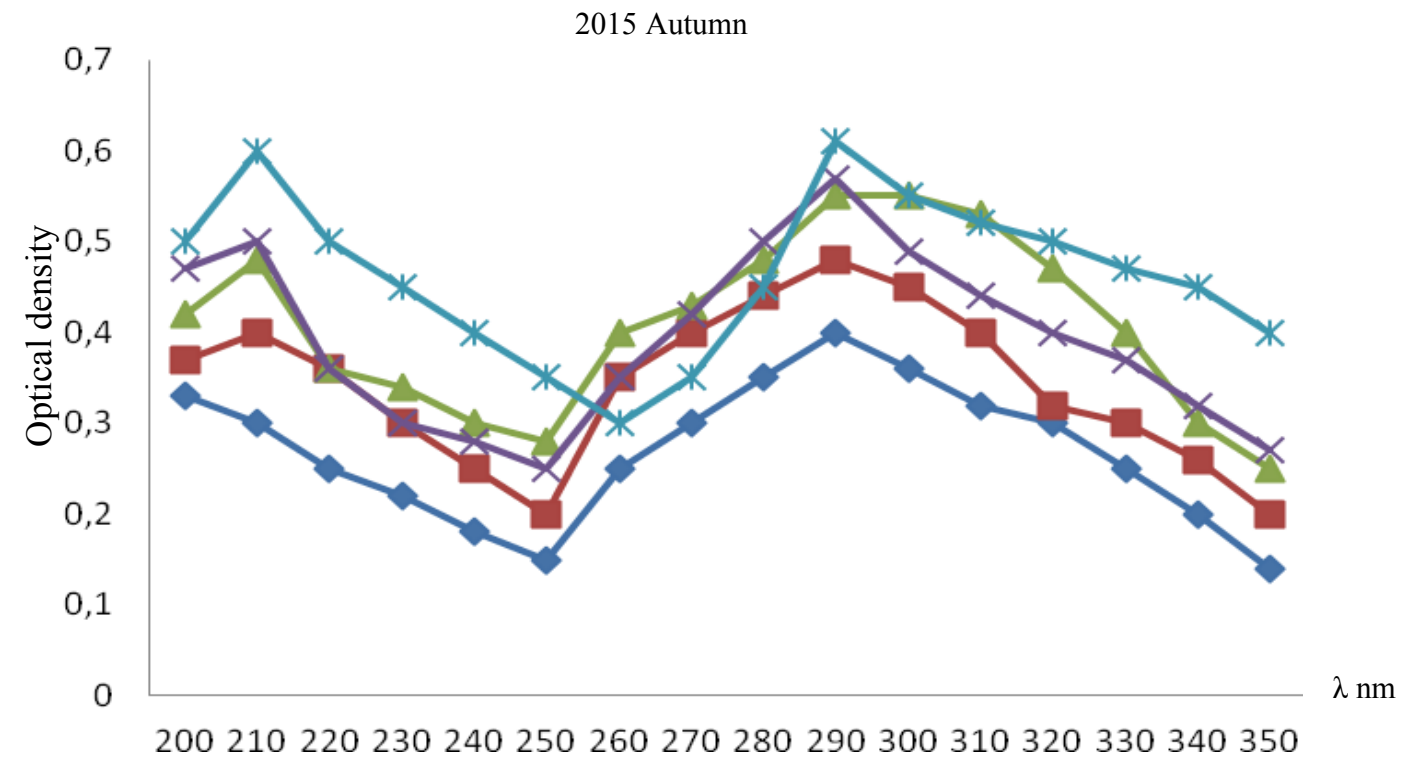

(b)

Fig. 2 The propolis $\mathbf{0 , 0 0 2} \%$-alcohol solution absorption spectra in ultra-violet areas.

1. Baghdati district.

2. Khoni district.

3. Sagarejo district.

4. Tskhaltubo district.

5. Chiatura district.

peak is a characteristic of phenolcarbonic acids, but at $290 \mathrm{~nm}$ - the absorption index characterizes polyphenols (flavanones). All samples of propolis were of high optical activity.

In order to determine the relations between optical density and antimicrobial activity, we have studied the antimicrobial activity of the samples of propolis by using the method of diffusion [23], on the bacterial strains: Candida, Escherichia coli, Staphulococcus aureus, Steptpcoccus pyogenes, streptococcus fecalis. The results are shown in Table 1 below. 
Table 1 Antimicrobial activity of propolis alcohol solution.

\begin{tabular}{lllllll}
\hline$\#$ & \multirow{2}{*}{ Name of microorganism } & \multicolumn{5}{c}{ Antimicrobial activity data } \\
\cline { 3 - 7 } & Baghdati & Tskhaltubo & Khoni & Chiatura & Sagarejo \\
\hline 1 & Candida & +++ & ++++ & ++++ & ++++ & +++ \\
2 & E. coli & +++ & ++++ & ++++ & ++++ & +++ \\
3 & Staphylococcus aureus & +++ & ++++ & ++++ & ++++ & ++++ \\
4 & Stephtococcus pyogenes & +++ & ++++ & ++++ & ++++ & ++++ \\
5 & strephtococcus fecalis & +++ & ++++ & ++++ & ++++ & ++++ \\
\hline Note:" $+++"$ means medium-sensitive, "++++" - sensitive.
\end{tabular}

All samples of propoils are characterized by antimicrobial activity (IC50-1mg/l).

\section{Results and Discussion}

The experiments conducted some years later have shown that Georgian propolis is characterized by a high optical density. Its alcohol solutions exhibit high antimicrobial activity. The sample with low optical density (from Baghdati district) has shown a relatively low antimicrobial activity.

High antimicrobial activity of Georgian propolis is conditioned by the nature of Georgia since almost all regions of Georgia are rich with plants containing polyphenols: chestnut (Castanea sativa Mill.),Poplar (Populus gracilis Grossh.), willow (Salix), etc.

We would like to express our appreciation to employees of Ballistic Research Laboratory of the G. Eliava Research Institute of Bacteriophage, Microbiology and Virology for the contribution in microbiological studies.

\section{Conclusion}

It may be noted that there exists a correlation between optical density and antimicrobial characteristic of Georgian propolis. Samples with high optical activity are characterized by high sensitivity toward microorganisms.

Optical activity of samples is conditioned by flavonoids, flavanones in particular.

Optical density is high in spring samples.

At $290 \mathrm{~nm}$ wave length, the sample (from Baghdati district) with low optical density is characterized by antimicrobial activity that is not conditioned by the amount of polyphenols, but by flavonoids.

\section{References}

[1] Bagrationi, D., and Yadigar, D. T. 2002. "The University Publishers." 178. (in Georgian)

[2] Kananeli. 1997. Irregular Medical Book. Tbilisi "ANALI", 365. (in Georgian)

[3] Bankova, V. 2007. "Natural Products Chemistry in the Third Millennium." Chem. Cent. J. 1: 1.

[4] Bankova, V. 2009. "Chemical Diversity of Propolis Makes It a Valuable Source of New Biologically Active Compounds." Journal of Api Product and Api Medicinal Science 1: 23-9.

[5] Hellgren, J., Cervin, A., Nordling, S., Bergman, A., and Cardell, L. O. A. 2010. "Uergic Rhinitis and the Common Cold-High Cost to Society." Allergy 65 (6): 776-83

[6] Koc, A. N., Silic, S., Multu-Sarioguzel, F., and Sagdic, O. 2007. "Antifungal Activity of Propolis in Fouar Differect Fruit Juices." Food Technology and Biotechnology 45: 57-61.

[7] Koc, A. N., Silic, S., Kasap, F., Hormet-Oz, H. T., Mavus-Buldu, H., and Erical, B. D. 2011. "Antofungal Activity of the Honey Bee Products against Candida spp. and Trichosporon spp." Journal of Medicinal Food 14 (1-2): 128-34.

[8] Kosalec, I., Pepoljinjak, S., Bakmaz, M., and Vladimir-Knezevic, S. 2005. "Flavonoid Analysis and Antimicrobial Activity of Commercially Available Propolis Products." Acta Pharmaceutica 55 (4): 423-30

[9] Kumar, N., Ahmad, M. K. K., Dang, R., and Husian, A. 2008. "Antioxydant and Antimicrobial Activity of Propolis from Tamil Nadu Zone." Journal of Medicinal Plants Research 2 (120): 361-4.

[10] Laskar, R. A., SK, I., Roy, N., and Begum, N. A. 2010. "Antioxydant Activity of Indian Propolis and Its Chemical Constituens." Food Chemistry 122 (1): 233-7.

[11] Alencar, S. M., Oldoni, T. L. C., Castio, M. L., et al. 2007. "Chemical Composition and Biological Activity of a New Type of Brazillian Propolis.” Journal of Ethnoparmacology 113 (7): 278-83.

[12] Banscota, A. H., Tezuka, Y., and Kadota, Y. 2001. 
"Recent Progress in Pharmacological Research of Propolis." Pitoterapy Research 15 (7): 561-71.

[13] Kalogeropoutos, N., Konteles, S. J., Troullidou, E., Meurtzinos, I., and Karathanos, V. T. 2009. "Chemical Composition Antioxydant Activity and Antimicrobial Propereties of Propolis Extracts from Greece and Cyprus." Food Chemistry 116 (2): 452-61.

[14] Pietta, P. G., Gardana, C., and Pietta, A. M. 2002. "Analytical Methods for Quality Control of Propolis." Fitoterapis 73 (1): S7-20.

[15] Sforcin, J. M. 2007. "Propolis and Immune Systsm: A Review.” Journal of Ethnoparmacology 113 (1): 1-14.

[16] Gabunia, K., Chumburidze, B., and Kunchulia, L. 1998. "The Regional Study of the Georgian Origin Propolis by the Spectrophotometrical Methrology." Kutaisi Medical Journal 2: 86-9.

[17] De Castro, S. L. 2001. "Propolis: Biological and Pharmacological Activies. Therapeutic Uses of This Bee Product." Annual Review of Biochemic Sciences 3: 49-83.

[18] Park, Y. K., Alencar, S. M., and Aguiar, C. L. 2002. "Botanical Origin and Chemical Composition of Brazillan
Propolis." J. of Agricultral and Food Chemistry 50 (9): 2502-6.

[19] Hendi, N. K. K., Naher, H. S., and Al-Charrakh, A. H. 2011. "In vitro Antibacterial and Antifungal Activity of Iraqi Propolis." Journal of Medicinal Plants Research 5 (20): 5058-66.

[20] Miguel, M. G., Nunes, S., Dandlen, S. A., Cavaco, A. M., and Antunes, M. D. 2010. "Phenols and Antioxydant Activity of Hydro-alcoholic Extr acts of Propolis from Algarve Seuth of Portugal." 2010. Food and Chemical Toxicology 48 (12): 3418-23.

[21] Popova, M., Bankova, V., Tsvetkova, I., and Kujungiev, A. "Comparative Study of the Biological Activity of Propolis Different Geographic Origin: A Statistical Opproach." Macedonialn Pharmacevtical Bulletin.

[22] Yaghoubi, M. J., Ghorbani, G., Soleimanian Zad, S., and Satari, R. 2007. "Antimicrobial Activity of Iranian Propolis and Its Chemical Composition.” Daru 15 (1): 45-8.

[23] Gabunia, K., Chumburidze, B., and Kunchulia, L. 2004. "Antimicrobical Activite of West Georgian Propolis." J. Georgian Medical News 5: 61-4. 